\title{
Drivers and modulators in the central auditory pathways
}

\author{
Charles C. Lee* and S. Murray Sherman \\ Department of Neurobiology, University of Chicago, Chicago, IL, USA
}

The classic view of auditory information flow depicts a simple serial route from the periphery through tonotopically-organized nuclei in the brainstem, midbrain and thalamus, ascending eventually to the neocortex. Yet, complicating this picture are numerous parallel ascending and descending pathways, whose roles in auditory processing are poorly defined. To address this ambiguity, we have identified several anatomical and physiological properties that distinguish the auditory glutamatergic pathways into two groups that we have termed "drivers" and "modulators". Driver pathways are associated with information-bearing pathways, while modulator pathways modify these principal information streams. These properties illuminate the potential roles of some previously ill-defined auditory pathways, and may be extended further to categorize either unknown or mischaracterized pathways throughout the auditory system.

Edited by:

Mriganka Sur, Massachusetts Institute of Technology, USA

Reviewed by:

Preston E. Garraghty, Indiana University, USA

Christoph E. Schreiner, University of California, San Francisco, USA

*Correspondence:

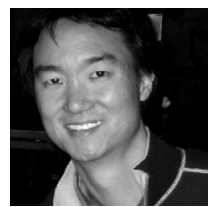

Charles C. Lee began his scientific training at the California Institute of Technology, where he received his B.Sc. with Honors in Chemistry and Biology. He earned his Ph.D. from the Department of Molecular and Cell Biology at the University of California at Berkeley under the mentorship of the late Prof. Jeffery A. Winer. His current research at the University of Chicago, under the mentorship of Prof. S. Murray Sherman, focuses on the neurobiological mechanisms supporting information processing in sensory systems. clee@bsd.uchicago.edu

\section{Keywords: drivers, modulators, inferior colliculus, medial geniculate body, thalamus, auditory cortex}

\section{INTRODUCTION}

The mammalian auditory system is challenged with the task of accurately encoding the pattern and source of incoming sound. Many of the initial steps involved in the manipulation of acoustic information already have been wellcharacterized (Webster, 1992; Winer, 2005). In the standard model, auditory information is first transmitted from the cochlea (Ryugo, 1992) to the cochlear nucleus (Cant, 1992), where it is distributed across multiple parallel ascending streams to the superior olivary complex, the lateral lemniscal nuclei (Schwartz, 1992), and the inferior colliculus (IC) (Oliver and Huerta, 1992). Subsequently, information is communicated to the medial geniculate body (MGB) of the thalamus (Winer, 1992), where it is then transferred to the primary auditory cortex and on to higher auditory cortical areas (Kaas and Hackett, 2000; Lee and Winer, 2008b).

The tonotopic organization of frequencyspecific channels established at the cochlea is one of the few organizing features that per- sist throughout the auditory pathway (Kandler et al., 2009). In the classical view, the principle route for auditory information traverses through these tonotopic nuclei at each level of processing. However, numerous parallel ascending (Winer, 2005) and descending (Winer, 2006) pathways complicate this simple picture, and their roles in audition have yet to be adequately elucidated. For example, the ascending pathways through the non-tonotopically organized nuclei and the large number of descending projections pose unanswered questions regarding their roles in auditory information processing.

Assessing the putative functions of such projections has been recently aided by anatomical and physiological findings that segregate the main glutamatergic pathways into two types (Sherman and Guillery, 1998) (Figure 1). The first type termed drivers are similar to the potent retinogeniculate projections in the visual system, and are likely the main conduits for the transmission of auditory information (Reichova and Sherman, 2004; Sherman and Guillery, 2006; 


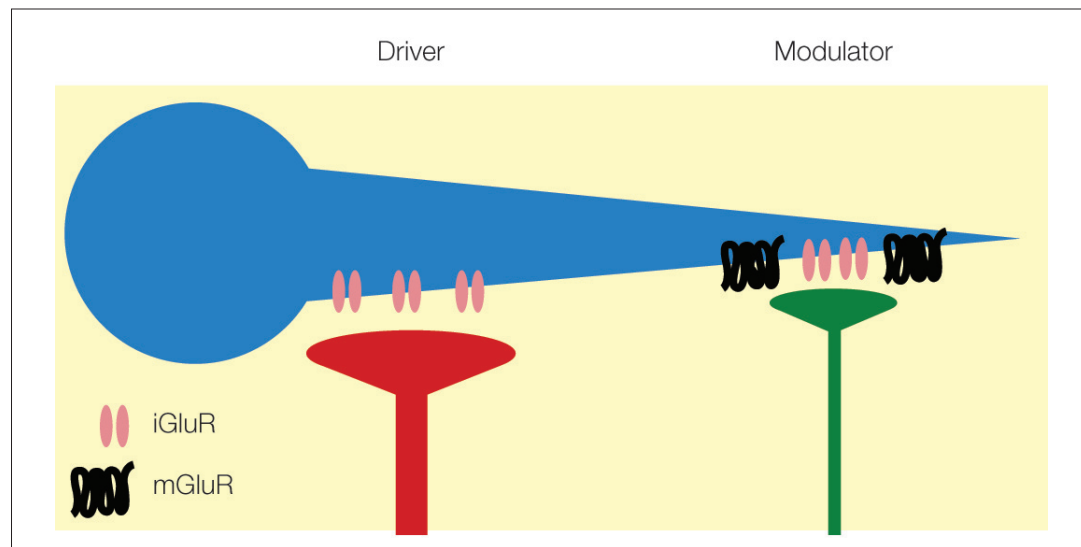

iGluRs only

Large EPSPS

Depressing synapse

Dense terminal arbors

Proximal dendrites

Thick axons

Figure 1 | Summary of anatomical and physiological properties of driver (red) and modulato (green) synapses onto a neuron (blue) (adapted from Lee and Sherman, 2009b). this has been extended across multiple synapses in the auditory system (Winer et al., 1999; Huang and Winer, 2000; Bartlett and Smith, 2002; Lee and Sherman, 2008, 2009b, 2010; Llano and Sherman, 2008).

The distinction between the two types of input derives in part from morphological observations of axonal arborizations. Driver input often resembles that of the retinal input to the lateral geniculate nucleus (LGN), which has been termed type 2 morphology by Guillery (1966). This morphological type has thick axons, dense terminal arbors (Guillery, 1966; Ralston, 1971; Famiglietti and Peters, 1972), and large endings that contact the proximal dendrites of relay cells (Winer et al., 1999; Llano and Sherman, 2008), often in triadic structures in glomeruli (Ralston, 1971; Famiglietti and Peters, 1972; Hamos et al., 1987). Like the retinal driver inputs, the driver projections produce large, all-or-none EPSPs by activating only ionotropic glutamate receptors (iGluRs), and they exhibit synaptic depression (Bartlett and Smith, 2002; Li et al., 2003; Reichova and Sherman, 2004) (Figure 1). In contrast, glutamatergic modulator inputs have different morphologies, called type 1 by Guillery (1966) and exemplified by the corticogeniculate feedback pathway from layer 6 of visual cortex. This morphological type has thin axons, sparse arbors, and small terminals ending on distal dendrites (Sherman and Guillery, 2006). Their physiological properties differ as well, exhibiting synaptic facilitation and producing small, graded EPSPs by engaging both iGluRs and metabotropic glutamate receptors (mGluRs) (Bartlett and Smith, 2002; Li et al., 2003; Reichova and Sherman, 2004) (Figure 1). These glutamatergic modulators should not be confused with the various neuromodulator pathways, such as those using acetylcholine (Varela and Sherman, 2007) and serotonin (Varela and Sherman, 2009) as neurotransmitters; their synaptic properties and roles may be very different.

These properties likely support the roles of driver and modulator pathways in information processing. Thus, driver synapses are likely highlyreliable and efficient transmitters of information, given their close proximity to the neuronal cell body and their high probability of transmitter release (Gil et al., 1999; Sherman and Guillery, 2006). Furthermore, the synaptic depression has been suggested to act as a dynamic gain control mechanism specific to the input, which is very useful in information flow as firing rates of the afferents change (Abbott et al., 1997). Modulator projections, with their distal dendritic locations, lower probability of transmitter release, and pro- 
First order nucleus

It is a thalamic nucleus that receives its primary driving input from peripheral afferents; examples are MGBv, LGN, VPm.

Higher order nucleus

It is a thalamic nucleus that receives driving input from layer 5 of a first order cortical area and relays that to another cortical area; examples are MGBd, LP-Pul, POm. longed responses from mGluRs, are less suited as conveyors of information (Stratford et al., 1996; Gil et al., 1999; Sherman and Guillery, 2006). However, the prolonged responses afforded by activation of mGluRs not only modulates such properties as overall excitability, but also provides control of many time- and voltage-gated ion channels in the target cell, a feature that is poorly controlled by driver inputs with their brief EPSPs (Sherman and Guillery, 2006); such prolonged mGluR responses would also act like low-pass temporal filters, resulting in less information transferred across the synapse (Sherman and Guillery, 2006).

These multiple anatomical and physiological criteria for distinguishing glutamatergic synapses have been useful for characterizing the auditory pathways from the IC, thalamus and cortex (Lee and Sherman, 2008, 2009b, 2010; Llano and Sherman, 2008), which we review below. These properties also provide the foundation for ongoing and future investigations of the information-bearing roles of the intracortical and corticocortical connections in the various auditory cortical areas.
FIRST ORDER

\section{AND HIGHER ORDER PATHWAYS}

The driver and modulator framework has been particularly useful in the delineation of forebrain sensory pathways, particularly in the parcellation of thalamic relays, which can be classified as either a first order nucleus (FO) or higher order nucleus (HO) (Sherman and Guillery, 2002, 2006), based on the source of their driving input. FO nuclei, such as the LGN, ventral division of the medial geniculate body (MGBv) and ventroposterior medial nucleus $(\mathrm{VPm})$, receive their principal driving input from peripheral sources, while $\mathrm{HO}$ nuclei, such as the pulvinar (LP-Pul), dorsal division of the MGB (MGBd), and posteromedial nucleus (POm), receive their driving input mainly from layer 5 of the cortex (Figure 2). Note that both FO and HO thalamic nuclei receive feedback modulatory input from cortical layer 6, but only $\mathrm{HO}$ nuclei, in addition, receive a feedforward driver input from cortical layer 5. Interestingly, this suggests that the $\mathrm{HO}$ thalamic relays transmit layer 5 driver input from one cortical area to the thalamic recipient layers of a second cortical area (Sherman and Guillery, 2002; Reichova and

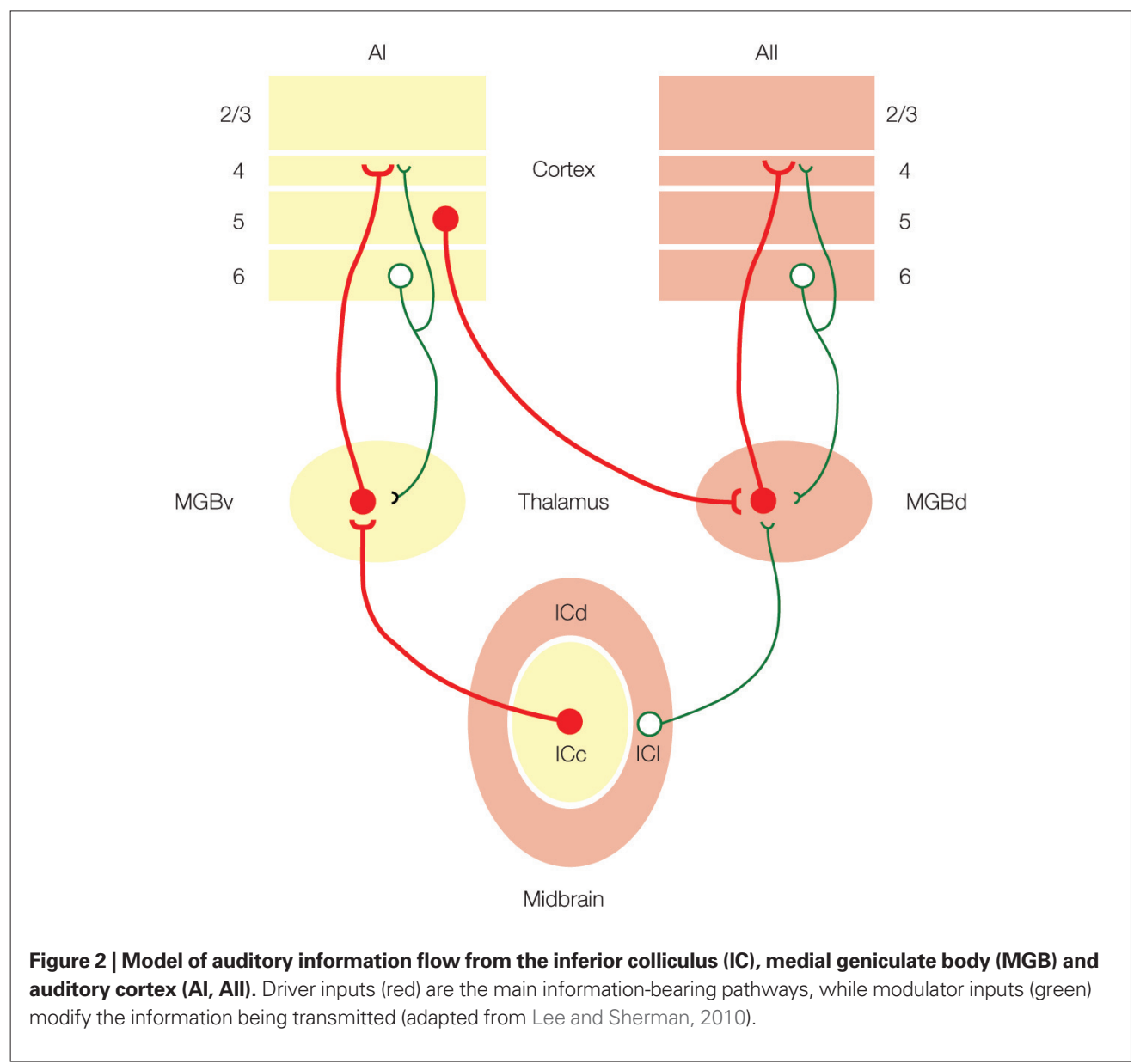


Sherman, 2004; Lee and Sherman, 2008), analogous to the FO transmission by the LGN of retinal input to the primary visual cortex (Figure 2), and likewise may utilize the unique operational modes of the thalamus, including gating and the different burst versus tonic firing modes of relay cells (Cox et al., 1998; Sherman, 2001). These distinctions between FO and HO pathways have particular relevance for the central auditory pathways, as we discuss below.

\section{INFERIOR COLLICULUS}

Among the main auditory centers, the IC is particularly salient as the site of convergence from downstream sources in the cochlear nucleus, superior olivary complex and the lateral lemniscal nuclei, as well as feedback projections from the auditory cortex (Oliver and Huerta, 1992), and thus represents a major hub for integrating ascending and descending processing streams. The central nucleus of the inferior colliculus (ICc) is the main tonotopically organized subdivision (Romand and Ehret, 1990; Malmierca et al., 2008), and is the principal source of information ascending to the MGBv (Winer, 2005). Surrounding the ICc are the lateral (ICl), dorsal (ICd), and caudal cortices of the IC (ICca), which we collectively refer to as the shell regions (ICs). These subdivisions are primarily non-tonotopically organized (Romand and Ehret, 1990; Malmierca et al., 2008), and project to the MGBd and medial (MGBm) divisions of the MGB (Wenstrup, 2005). Interestingly, the role of these non-lemniscal projections to the MGB are not well-defined $(\mathrm{Hu}$, 2003; Wenstrup, 2005).

Previous models have suggested that the ascending tectothalamic pathways from the ICc and ICs to the MGBv, MGBd and MGBm, respectively, represent parallel paths for the flow of auditory information (Hu et al., 1994; Hu, 2003; Wenstrup, 2005). However, recent studies now support an alternative scheme (Figure 2). These data demonstrate that the tectothalamic synapse from the ICc exhibits properties associated with driver synapses (Bartlett and Smith, 2002; Lee and Sherman, 2010), while the ICs projection instead has modulator characteristics (Bartlett and Smith, 2002; Smith et al., 2007; Lee and Sherman, 2010) (Table 1). Thus, in the alternative model of auditory tectothalamic transmission, the main information-bearing pathway is proposed to arise primarily from the ICc, while the pathway from the ICs instead modulates information flow through the higher order auditory thalamus (Figure 2) (Bartlett and Smith, 2002; Smith et al., 2007; Lee and Sherman, 2010). Interestingly, the source of the driving inputs to the higher order auditory thalamic nuclei instead arises from layer 5 of the primary auditory cortex (see above) (Figure 2) (Bartlett and Smith, 2002; Llano and Sherman, 2008). Thus, the tectothalamic projection from ICs should act to modulate the corticothalamocortical processing stream through the higher order auditory thalamus (Sherman and Guillery, 2006; Lee and Sherman, 2010).

\section{MEDIAL GENICULATE BODY}

Information ascending to the auditory cortex must first be conveyed through the MGB of the thalamus, yet the importance of the MGB in audition extends beyond a role as merely a relay (Sherman and Guillery, 2006; Lee and Sherman, 2008; Lee and Winer, 2008a). Of the main MGB nuclei, the $\mathrm{MGBv}$ is the primary conduit for tonotopic information ascending to the primary auditory cortex, whereas the MGBd and MGBm divisions are not tonotopically organized and project broadly to non-tonotopic, multimodal and limbic related areas (Kaas and Hackett, 2000; Lee and Winer, 2008a; Llano and Sherman, 2008). The MGB also receives major projections from layers 5 and 6 of the auditory cortex (Winer et al., 2001; Llano and Sherman, 2008), which either transmit or modulate information through the thalamus (see below) (Figure 2).

The thalamocortical projections from the non-tonotopic nuclei of the MGB have been presumed to perform alternative functions, such as regulating attention (Olshausen et al., 1993), and not generally regarded as informationbearing pathways to higher auditory areas. This view is challenged by findings that demonstrate anatomical and physiological similarity among the thalamocortical projections from the MGBv and MGBd (Huang and Winer, 2000; Rose and Metherate, 2001; Llano and Sherman, 2008; Lee and Sherman, 2009b). Morphologically, these thalamocortical projections have large, dense, bushy arborizations in layer 4 that extend into layer 3 (Huang and Winer, 2000; Llano and Sherman, 2008). Physiologically, these projections demonstrate large EPSPs that depress in response to paired-pulse stimulation and lack a metabotropic glutamate component (Rose and Metherate, 2001; Lee and Sherman, 2009b).

Thus, projections from both the MGBv and MGBd share driver-like properties (Table 1), and suggest that the projections from the MGBd have a role similar to that of the MGBv, i.e., as an information-bearing pathway to the higher auditory cortical areas (Figure 2). The main distinction between them is that $\mathrm{MGBv}$ is an FO relay, while MGBd is an HO relay (see above). An interesting question remaining concerns the 
Table 1 | Driver and modulator properties of the central auditory pathways.

\begin{tabular}{|c|c|c|c|c|c|c|c|}
\hline & ICc to MGBv & MGBv to Al & MGBd to All & L5 to MGBd & $\mathrm{ICI}$ to $\mathrm{MGBd}$ & L6 to MGBv & L6 to L4 \\
\hline $\begin{array}{l}\text { Large } \\
\text { EPSPs }\end{array}$ & $\begin{array}{l}\text { Bartlett } \\
\text { and Smith (2002), } \\
\text { Lee and Sherman } \\
\text { (2010) }\end{array}$ & $\begin{array}{l}\text { Lee } \\
\text { and Sherman } \\
\text { (2008), Rose } \\
\text { and Metherate } \\
\text { (2001) }\end{array}$ & $\begin{array}{l}\text { Lee } \\
\text { and Sherman } \\
\text { (2008) }\end{array}$ & & & & \\
\hline $\begin{array}{l}\text { Small } \\
\text { EPSPs }\end{array}$ & & & & & $\begin{array}{l}\text { Bartlett and Smith } \\
\text { (2002), Lee and } \\
\text { Sherman (2010) }\end{array}$ & $\begin{array}{l}\text { Bartlett and } \\
\text { Smith (2002) }\end{array}$ & $\begin{array}{l}\text { Lee and } \\
\text { Sherman } \\
\text { (2009b) }\end{array}$ \\
\hline $\begin{array}{l}\text { Depressing } \\
\text { synapses }\end{array}$ & $\begin{array}{l}\text { Bartlett } \\
\text { and Smith (2002), } \\
\text { Lee and Sherman } \\
\text { (2010) }\end{array}$ & $\begin{array}{l}\text { Lee } \\
\text { and Sherman } \\
\text { (2008), Rose } \\
\text { and Metherate } \\
\text { (2001) }\end{array}$ & $\begin{array}{l}\text { Lee } \\
\text { and Sherman } \\
\text { (2008) }\end{array}$ & & & & \\
\hline $\begin{array}{l}\text { Facilitating } \\
\text { synapse }\end{array}$ & & & & & $\begin{array}{l}\text { Bartlett and Smith } \\
\text { (2002), Lee and } \\
\text { Sherman (2010) }\end{array}$ & $\begin{array}{l}\text { Bartlett and } \\
\text { Smith (2002) }\end{array}$ & $\begin{array}{l}\text { Lee and } \\
\text { Sherman } \\
\text { (2009b) }\end{array}$ \\
\hline iGluRs only & $\begin{array}{l}\text { Bartlett } \\
\text { and Smith (2002), } \\
\text { Lee and Sherman } \\
\text { (2010) }\end{array}$ & $\begin{array}{l}\text { Lee } \\
\text { and Sherman } \\
\text { (2008) }\end{array}$ & $\begin{array}{l}\text { Lee } \\
\text { and Sherman } \\
\text { (2008) }\end{array}$ & & & & \\
\hline $\begin{array}{l}\text { iGluRs and } \\
\text { mGluRs }\end{array}$ & & & & & $\begin{array}{l}\text { Bartlett and Smith } \\
\text { (2002), Lee and } \\
\text { Sherman (2010) }\end{array}$ & $\begin{array}{l}\text { Bartlett and } \\
\text { Smith (2002) }\end{array}$ & $\begin{array}{l}\text { Lee and } \\
\text { Sherman } \\
\text { (2009b) }\end{array}$ \\
\hline $\begin{array}{l}\text { Dense } \\
\text { terminal } \\
\text { arbors }\end{array}$ & $\begin{array}{l}\text { Bartlett } \\
\text { and Smith (2002), } \\
\text { Bartlett et al. } \\
(2000)\end{array}$ & $\begin{array}{l}\text { Huang } \\
\text { and Winer (2000), } \\
\text { Llano and } \\
\text { Sherman (2008) }\end{array}$ & $\begin{array}{l}\text { Huang and } \\
\text { Winer (2000), } \\
\text { Llano } \\
\text { and Sherman } \\
\text { (2008) }\end{array}$ & $\begin{array}{l}\text { Bartlett et al. } \\
\text { (2000), Llano and } \\
\text { Sherman (2008), } \\
\text { Ojima (1994), } \\
\text { Winer et al. (1999, } \\
\text { 2001) }\end{array}$ & & & \\
\hline $\begin{array}{l}\text { Sparse } \\
\text { terminal } \\
\text { arbors }\end{array}$ & & & & & $\begin{array}{l}\text { Bartlett and Smith } \\
\text { (2002), Bartlett } \\
\text { et al. (2000), Huang } \\
\text { and Winer (2000), } \\
\text { Smith et al. (2007) }\end{array}$ & $\begin{array}{l}\text { Bartlett and } \\
\text { Smith (2002), } \\
\text { Llano } \\
\text { and Sherman } \\
\text { (2008), Ojima } \\
\text { (1994), Winer } \\
\text { et al. (2001) }\end{array}$ & $\begin{array}{l}\text { Prieto } \\
\text { and Winer } \\
\text { (1999) }\end{array}$ \\
\hline Thick axons & $\begin{array}{l}\text { Bartlett } \\
\text { and Smith (2002), } \\
\text { Bartlett et al. } \\
(2000)\end{array}$ & $\begin{array}{l}\text { Huang } \\
\text { and Winer (2000), } \\
\text { Llano and } \\
\text { Sherman (2008) }\end{array}$ & $\begin{array}{l}\text { Huang and } \\
\text { Winer (2000), } \\
\text { Llano } \\
\text { and Sherman } \\
\text { (2008) }\end{array}$ & $\begin{array}{l}\text { Bartlett et al. } \\
\text { (2000), } \\
\text { Llano and } \\
\text { Sherman (2008), } \\
\text { Ojima (1994), } \\
\text { Winer et al. (1999, } \\
\text { 2001) }\end{array}$ & & & \\
\hline Thin axons & & & & & $\begin{array}{l}\text { Bartlett and Smith } \\
\text { (2002), Bartlett } \\
\text { et al. (2000), } \\
\text { Huang and Winer } \\
\text { (2000), Smith et al. } \\
\text { (2007) }\end{array}$ & $\begin{array}{l}\text { Bartlett and } \\
\text { Smith (2002), } \\
\text { Llano and } \\
\text { Sherman } \\
\text { (2008), Ojima } \\
\text { (1994), Winer } \\
\text { et al. (2001) }\end{array}$ & $\begin{array}{l}\text { Prieto } \\
\text { and } \\
\text { Winer } \\
\text { (1999) }\end{array}$ \\
\hline
\end{tabular}

Grey shading: Driver properties

White shading: Modulator properties 
thalamocortical projections to layer 1 from the MGBm (Huang and Winer, 2000; Jones, 2009), part of the "matrix" system defined by Jones (2009), whose role remains to be defined. Thus, although it is generally regarded simply a relay of ascending auditory information, the MGB has important roles ranging from the transformation of auditory information (Miller et al., 2001) to continuing the flow of intraareal processing in the cortex (see below) (Sherman and Guillery, 2006; Lee and Sherman, 2008).

\section{AUDITORY CORTEX}

The auditory cortex is the ultimate target for information ascending from the periphery through the MGB (Lee and Winer, 2008a,b; Llano and Sherman, 2008). Similar to lower stations, tonotopy is an organizing feature of the primary auditory cortex $(\mathrm{AI})$, but is absent in the surrounding non-tonotopic and multimodal areas, such as the secondary auditory area (AII) (Stiebler et al., 1997; Kaas and Hackett, 2000; Lee et al., 2004). The size and number of these auditory cortical areas varies among species, e.g., there are two tonotopic areas in the mouse (Stiebler et al., 1997), three in the monkey (Hackett et al., 1998) and five in the cat (Reale and Imig, 1980). Yet, an unresolved issue is: how do these multiple areas interact to compute features in the auditory scene?

In the standard hierarchical cortical model of auditory processing, information is sent progressively via direct corticocortical connections from lower auditory areas, such as AI, to higher auditory areas, such as AII (Felleman and Van Essen, 1991; Rouiller et al., 1991). Such successive convergence of auditory inputs purportedly accounts for the increasingly complicated receptive fields of higher auditory areas, such as AII (Schreiner and Cynader, 1984). Interestingly, the synaptic properties of these direct corticocortical connections have not been examined until recently (Covic et al., 2009), and their salience is questionable, given recent findings that suggest an alternate route for interareal processing via a corticothalamocortical route (Figure 2) (Reichova and Sherman, 2004; Sherman and Guillery, 2006; Lee and Sherman, 2008; Llano and Sherman, 2008; Theyel et al., 2010).

The alternate corticothalamocortical route for interareal auditory processing is enabled by driver projections that originate from layer 5 of the primary auditory cortex and synapses in the higher order auditory thalamus, i.e., MGBd (Table 1) (Ojima, 1994; Winer et al., 1999; Llano and Sherman, 2008). These feedforward CT projections are distinguished from the feedback layer 6 projections, which exhibit modulator charac- teristics and project to the originating thalamic nucleus, e.g., AI to MGBv (Table 1) (Ojima, 1994; Bartlett et al., 2000; Winer et al., 2001; Bartlett and Smith, 2002). Thus, the AI layer 5 inputs to MGBd, in conjunction with the driver thalamocortical projections from MGBd to AII (see above), establish a transthalamic route for the interareal transfer of auditory information (Figure 2). This alternate route does not negate the potential information-bearing roles of the direct corticocortical projections (Rockland and Pandya, 1979; Lee and Winer, 2008b), which are composed of an intricate pattern of laminar-specific driver and modulator projections (Covic et al., 2009). Thus, auditory forebrain computations involve multiple processes beyond those suggested by simple cortical hierarchies (Felleman and Van Essen, 1991; Rouiller et al., 1991).

Finally, intrinsic cortical microcircuits further transform auditory information before redistribution through the cortical network (Feldmeyer and Sakmann, 2000; Silberberg et al., 2004; Hirsch and Martinez, 2006a). Yet, information processing among cortical layers within an auditory area still remains unresolved. This issue is complicated by the complexity and floridness of intrinsic cortical interconnections, which account for almost half of the input to a cortical column (Ahmed et al., 1994; Latawiec et al., 2000; Binzegger et al., 2004; Lee et al., 2004). One potential driving circuit extends from layer 4 to layers $2 / 3$ and then to layer 5 (Hirsch and Martinez, 2006b; Lee and Sherman, 2009a), and then outputs to the higher order thalamus (Ojima, 1994; Winer et al., 1999; Llano and Sherman, 2008), but the bulk of intrinsic connections may be instead more likely to exhibit modulator properties, such as the layer 6 to layer 4 projections (Ahmed et al., 1994; Stratford et al., 1996; Prieto and Winer, 1999; TarczyHornoch et al., 1999; Lee and Sherman, 2008, 2009b). In this manner, functional connectivity within the auditory cortex may resemble that in the thalamus, where synaptic weight is inversely proportional to anatomical weight (Binzegger et al., 2004; Sherman and Guillery, 2006).

\section{CONCLUSION}

The driver and modulator framework adds a unique perspective to our ongoing understanding of the central auditory pathways. As such, these properties may fruitfully be applied to other pathways of interest throughout the auditory system, such as the thalamoamygdaloid pathway (Doron and Ledoux, 1999). However, open questions remain for future investigation. 
For instance, how do driver and modulator pathways interact functionally to construct auditory receptive fields? Do pathways differ according to age and experience? And, how do these properties extend across systems and species? Indeed, the utility of this framework is not constrained to the auditory modality, as its relevance in other sensory systems has already been established (Reichova and Sherman, 2004; Petrof and Sherman, 2009), but has not yet been extended to non-mammalian species. In this respect, a comparative approach that extends the investigation of these properties in other organisms may lend unique insights into the ontogeny, development and evolution of the sensory pathways in higher organisms.

\section{ACKNOWLEDGMENTS}

We thank the late Jeffery A. Winer for his past mentorship and guidance (to C.C.L.). This work was supported by the National Institutes of Health grants F32NS054478 (CCL), and R01EY003038 and R01DC008794 (SMS).

\section{REFERENCES}

Abbott, L. F., Varela, J. A., Sen, K., and Nelson, S. B. (1997). Synaptic depression and cortical gain control.Science $275,220-224$.

Ahmed, B., Anderson, J. C., Douglas, R. J., Martin, K. A. C., and Nelson, J. C. (1994). Polyneuronal innervation of spiny stellate neurons in cat visual cortex. J. Comp. Neurol. 341, 39-49.

Bartlett, E. L., and Smith, P. H. (2002). Effects of paired-pulse and repetitive stimulation on neurons in the rat medial geniculate body. Neuroscience 113, 957-974.

Bartlett,E.L.,Stark,J.M., Guillery,R.W., and Smith, P. H. (2000). Comparison of the fine structure of cortical and collicular terminals in the rat medial geniculate body. Neuroscience 100, 811-828.

Binzegger, T., Douglas, R. J., and Martin, K. A. (2004). A quantitative map of the circuit of cat primary visual cortex. $J$. Neurosci. 24, 8441-8453.

Cant, N. B. (1992). The cochlear nucleus: neuronal types and their synaptic organization. In Springer Handbook of Auditory Research, Vol. 1, The Mammalian Auditory Pathway: Neuroanatomy, D. B. Webster, A. N. Popper and R. R. Fay, eds (New York, Springer), pp. 66-116.

Covic, E. N., Farmer, L., Petrof, I., and Sherman, S. M. (2009). Functional characterization of directly projecting feed-back auditory corticocortical connections. Proc. Soc. Neurosci. 35, 452.3 .

Cox, C. L., Zhou, Q., and Sherman, S. M. (1998). Glutamate locally activates dendritic outputs of thalamic interneurons. Nature 394, 478-482.

Doron, N. N., and Ledoux, J. E. (1999). Organization of projections to the lateral amygdala from auditory and visual areas of the thalamus in the rat. J. Comp. Neurol. 412, 383-409.

Famiglietti, E. V. J., and Peters, A. (1972). The synaptic glomerulus and the intrinsic neuron in the dorsal lateral geniculate nucleus of the cat. J. Comp. Neurol. 144, 285-334.
Feldmeyer, D., and Sakmann, B. (2000). Synaptic efficacy and reliability of excitatory connections between the principal neurones of the input (layer 4) and output layer (layer 5) of the neocortex. J. Physiol. (Lond.) 525 (Pt 1), 31-39.

Felleman, D. J., and Van Essen, D. C. (1991). Distributed hierarchical processing in the primate cerebral cortex. Cereb. Cortex 1, 1-47.

Gil, Z., Connors, B. W., and Amitai, Y. (1999). Efficacy of thalamocortcal synaptic connections: quanta, innervation, and reliability. Neuron 23 , 385-397.

Guillery, R. W. (1966). A study of Golgi preparations from the dorsal lateral geniculate nucleus of the adult cat. $J$. Comp. Neurol. 128, 21-50.

Hackett, T. A., Stepniewska, I., and Kaas, J. H. (1998). Subdivisions of auditory cortex and ipsilateral cortical connections of the parabelt auditory cortex in macaque monkeys. J. Comp. Neurol. 394, 475-495.

Hamos, J.E., Van Horn, S. C., Raczkowski, D., and Sherman, S. M. (1987) Synaptic circuits involving an individual retinogeniculate axon in the cat. J. Comp. Neurol. 259, 165-192.

Hirsch, J. A., and Martinez, L. M. (2006a). Circuits that build visual cortical receptive fields. Trends Neurosci. 29, 30-39.

Hirsch, J. A., and Martinez, L. M. (2006b). Laminar processing in the visual cortical column. Curr. Opin. Neurobiol. 16, 377-384.

Hu, B. (2003). Functional organization of lemniscal and nonlemniscal auditory thalamus. Exp. Brain Res. 153, 543-549.

$\mathrm{Hu}, \mathrm{B}$., Senatorov, V., and Mooney, D. (1994). Lemniscal and non-lemniscal synaptic transmission in rat auditory thalamus. J. Physiol. (Lond.) 479, 217-231.

Huang, C. L., and Winer, J. A. (2000). Auditory thalamocortical projections in the cat: laminar and areal patterns of input. J. Comp. Neurol. 427, 302-331.
Jones, E. G. (2009). Synchrony in the interconnected circuitry of the thalamus and cerebral cortex. Ann. N. Y. Acad. Sci. 1157, 10-23.

Kaas, J. H., and Hackett, T. A. (2000). Subdivisions of auditory cortex and processing streams in primates. Proc. Natl. Acad. Sci. U.S.A. 97 11793-11799.

Kandler, K., Clause, A., and Noh, J. (2009). Tonotopic reorganization of developing auditory brainstem circuits. Nat. Neurosci. 12, 711-717.

Latawiec,D., Martin,K.A., and Meskenaite, V. (2000). Termination of the geniculocortical projection in the striate cortex of the monkey: a quantitative immunoelectron microscope study. J. Comp. Neurol. 419, 306-319.

Lee, C. C., Imaizumi, K., Schreiner, C. E., and Winer, J. A. (2004). Concurrent tonotopic processing streams in auditory cortex. Cereb. Cortex 14 441-451.

Lee, C. C., and Sherman, S. M. (2008). Synaptic properties of thalamic and intracortical intputs to layer 4 of the first- and higher-order cortical areas in the auditory and somatosensory systems. J. Neurophysiol. 100 317-326.

Lee, C. C., and Sherman, S. M. (2009a). Intrinsic cortical circuits of the primary and secondary areas of the mouse auditory cortex. Proc. Soc. Neurosci. 35, 452.2.

Lee, C. C., and Sherman, S. M. (2009b) Modulator property of the intrinsic cortical projections from layer 6 to layer 4. Front. Syst. Neurosci. 3:3. doi: 10.3389/neuro.06.003.2009.

Lee, C. C., and Sherman, S. M. (2010) Topography and physiology of ascending streams in the auditory tectothalamic pathway. Proc. Natl. Acad. Sci. U.S.A. 107, 372-377.

Lee, C. C., and Winer, J. A. (2008a). Connections of cat auditory cortex: I. Thalamocortical system. J. Comp. Neurol. 507, 1879-1900.

Lee, C. C., and Winer, J. A. (2008b). Connections of cat auditory cortex:
III. Corticocortical system. J. Comp. Neurol. 507, 1920-1943.

Li, J., Guido, W., and Bickford, M. E. (2003). Two distinct types of corticothalamic EPSPs and their contribution to short-term synaptic plasticity. J. Neurophysiol. 90, 3429-3440.

Llano, D. A., and Sherman, S. M. (2008). Evidence for non-reciprocal organization of the mouse auditory thalamocortical-corticothalamic projections systems. J. Comp. Neurol. 507, 1209-1227.

Malmierca, M. S., Izquierdo, M. A. Cristaudo, S., Hernández, O. Pérez-González, D., Covey, E., and Oliver, D. L. (2008). A discontinuous tonotopic organization in the inferior colliculus of the rat. J. Neurosci. 28, 4767-4776.

Miller, L. M., Escabí, M. A., Read, H. L., and Schreiner, C. E. (2001). Functional convergence of response properties in the auditory thalamocortical system. Neuron 32, 151-160.

Ojima, H. (1994). Terminal morphology and distribution of corticothalamic fibers originating from layers 5 and 6 of cat primary auditory cortex. Cereb. Cortex 4, 646-663.

Oliver, D. L., and Huerta, M. F. (1992) Inferior and superior colliculi. In Springer Handbook of Auditory Research, Vol. 1, The Mammalian Auditory Pathway: Neuroanatomy, D. B. Webster, A. N. Popper and R. R Fay, eds (New York, Springer-Verlag), pp. 168-221.

Olshausen, B. A., Anderson, C. H., and Van Essen, D. C. (1993). A neurobiological model of visual attention and invariant pattern recognition based on dynamic routing of information. J. Neurosci. 16, 1180-1192.

Petrof, I., and Sherman, S. M. (2009). Synaptic properties of the mammillary and cortical afferents to the anterodorsal thalamic nucleus in the mouse. $J$. Neurosci. 29, 7815-7819.

Prieto, J. J., and Winer, J. A. (1999). Layer VI in cat primary auditory cortex: Golgi study and sublaminar origins of 
projection neurons. J. Comp. Neurol 404, 332-358.

Ralston, H. J., III (1971). Evidence for presynaptic dendrites and a proposal for their mode of action. Nature 230, 585-587.

Reale, R. A., and Imig, T. J. (1980). Tonotopic organization in auditory cortex of the cat. J. Comp. Neurol. 182, 265-291.

Reichova, I., and Sherman, S. M. (2004). Somatosensory corticothalamic projections: distinguishing drivers from modulators. J. Neurophysiol. 92, 2185-2197.

Rockland, K. S., and Pandya, D. N. (1979). Laminar origins and terminations of cortical connections of the occipital lobe in the rhesus monkey. Brain Res. 179, 3-20.

Romand, R., and Ehret, G. (1990). Development of tonotopy in the inferior colliculus. I. Electrophysiological mapping in house mice. Brain Res. Dev. Brain Res. 54, 221-234.

Rose, H. J., and Metherate, R. (2001). Auditory thalamocortical transmission is reliable and temporally precise. J. Neurophysiol. 106, 331-340.

Rouiller, E. M., Simm, G. M., Villa, A. E. P., de Ribaupierre, Y., and de Ribaupierre, F. (1991). Auditory corticocortical interconnections in the cat: evidence for parallel and hierarchical arrangement of the auditory cortical areas. Exp. Brain Res. 86, 483-505.

Ryugo, D. K. (1992). The auditory nerve: peripheral innervation, cell body morphology, and central projections. In Springer Handbook of Auditory Research, Vol. 1, The Mammalian Auditory Pathway: Neuroanatomy, D. B. Webster, A. N. Popper and R. R. Fay, eds (New York, Springer), pp. 23-65.
Schreiner, C.E., and Cynader, M. S. (1984). Basic functional organization of second auditory cortical field (AII) of the cat. J. Neurophysiol. 51, 1284-1305.

Schwartz, I. R. (1992). The superior olivary complex and lateral lemniscal nuclei. In Springer Handbook of Auditory Research, Vol. 1, The Mammalian Auditory Pathway: Neuroanatomy, D. B. Webster, A. N. Popper and R. R. Fay, eds (New York, Springer), pp. 117-167.

Sherman, S. M. (2001). Tonic and burst firing: dual modes of thalamocortical relay. Trends Neurosci. 24, 122-126.

Sherman, S. M., and Guillery, R. W. (1998). On the actions that one nerve cell can have on another: distinguishing "drivers" from "modulators". Proc. Natl. Acad. Sci. U.S.A. 95, 7121-7126.

Sherman, S. M., and Guillery, R. W. (2002). The role of the thalamus in the flow of information to the cortex. Philos. Trans. R. Soc. Lond. B, Biol. Sci. 357, 1695-1708.

Sherman, S. M., and Guillery, R.W.(2006). Exploring the Thalamus and its Role in Cortical Function, 2nd edn. London, MIT Press.

Silberberg, G., Wu, C., and Markram, H. (2004). Synaptic dynamics control the timing of neuronal excitation in the activated neocortical microcircuit. $J$. Physiol. (Lond.) 556 (Pt 1), 19-27.

Smith, P. H., Bartlett, E. L., and Kowalkowski, A. (2007). Cortical and collicular inputs to cells in the rat paralaminar thalamic nuclei adjacent to the medial geniculate body. $J$. Neurophysiol. 2007, 681-695.

Stiebler, I., Neulist, R., Fichtel, I., and Ehret, G. (1997). The auditory cortex of the house mouse: left-right differences, tonotopic organization and quantitative analysis of frequency representation. J. Comp. Physiol. A 181, 559-571.

Stratford, K. J., Tarczy-Hornoch, K. Martin, K. A. C., Bannister, N. J., and Jack, J. J. B. (1996). Excitatory synaptic inputs to spiny stellate cells in cat visual cortex. Nature 382, 258-261.

Tarczy-Hornoch, K., Martin, K. A. C., Stratford, K. J., and Jack, J. J. B. (1999). Intracortical excitation of spiny neurons in layer 4 of cat striate cortex in vitro. Cereb. Cortex 9, 833-843.

Theyel, B. B., Llano, D. A., and Sherman, S. M. (2010). The corticothalamocortical circuit drives higher order cortex in the mouse. Nat. Neurosci. $13,84-88$.

Varela, C., and Sherman, S. M. (2007). Differences in response to muscarinic activation between first and higher order thalamic relays. J. Neurophysiol. 98, 3538-3547.

Varela, C., and Sherman, S. M. (2009) Differences in response to serotonergic activation between first and higher order thalamic nuclei. Cereb. Cortex 19, 1776-1786.

Webster, D. B. (1992). An overview of mammalian auditory pathways with a special emphasis on humans. In Springer Handbook of Auditory Research, Vol. 1, The Mammalian Auditory Pathway: Neuroanatomy, D. B. Webster, A. N. Popper and R. R. Fay, eds (New York, Springer), pp. $1-22$

Wenstrup, J. J. (2005). The tectothalamic system. In The Inferior Colliculus, J.A. Winer and C. E. Schreiner, eds (New York, Springer), pp. 200-230.

Winer, J. A. (1992). The functional architecture of the medial geniculate body and the primary auditory cortex.
In Springer Handbook of Auditory Research, Vol. 1, The Mammalian Auditory Pathway: Neuroanatomy, D. B. Webster, A. N. Popper and R. R. Fay, eds (New York, Springer-Verlag), pp. 222-409.

Winer, J. A. (2005). The central auditory system: a functional analysis. In The Inferior Colliculus, J. A. Winer and C. E. Schreriner, eds (New York, SpringerVerlag), pp. 1-68.

Winer, J. A. (2006). Decoding the auditory corticofugal systems. Hear. Res. 212, 1-8.

Winer, J. A., Diehl, J. J., and Larue, D. T. (2001). Projections of auditory cortex to the medial geniculate body of the cat. J. Comp. Neurol. 430, 27-55.

Winer, J. A., Larue, D. T., and Huang, C. L. (1999). Two systems of giant axons terminals in the cat medial geniculate body: convergence of cortical and GABAergic inputs. J. Comp. Neurol. 413, 181-197.

Conflict of Interest Statement: The authors declare that the research was conducted in the absence of any commercial or financial relationships that could be construed as a potential conflict of interest.

Received: 14 December 2009; paper pending published: 15 January 2010; accepted: 26 January 2010; published: 15 April 2010 Citation: Front. Neurosci. (2010) 4, 1: 79-86. doi: 10.3389/neuro.01.014.2010

Copyright $(2010$ Lee and Sherman. This is an open-access publication subject to an exclusive license agreement between the authors and the Frontiers Research Foundation, which permits unrestricted use, distribution, and reproduction in any medium, provided the original authors and source are credited. 